\title{
Virtual screening and evaluation of Ketol-Acid Reducto-Isomerase (KARI) as a putative drug target for Aspergillosis
}

\author{
Vivek K Morya ${ }^{1 *}$, Shalini Kumari ${ }^{2}$ and Eun-ki Kim ${ }^{1 *}$
}

\author{
* Correspondence: \\ moryavivek@gmail.com; \\ ekkim@inha.ac.kr \\ ${ }^{1}$ Department of Biological \\ Engineering, Inha University, \\ Incheon, Republic of Korea, 402- \\ 751 \\ Full list of author information is \\ available at the end of the article
}

\begin{abstract}
Aspergillus is a leading causative agent for fungal morbidity and mortality in immuno-compromised patients. To identify a putative target to design or identify new antifungal drug, against Aspergillus is required. In our previous work, we have analyzed the various biochemical pathways, and we found Ketol Acid ReductoIsomerase (KARI) an enzyme involves in the amino acid biosynthesis, could be a better target. This enzyme was found to be unique by comparing to host proteome through BLASTp analysis. A homology based model of KARI was generated by Swiss model server. The generated model had been validated by PROCHECK and WHAT IF programs. The Zinc library was generated within the limitation of the Lipinski rule of five, for docking study. Based on the dock-score six molecules have been studied for ADME/TOX analysis and subjected for pharmacophore model generation. The Zinc ID of the potential inhibitors is ZINC00720614, ZINC01068126, ZINC0923, ZINC02090678, ZINC00663057 and ZINC02284065 and found to be pharmacologically active agonist and antagonist of KARI. This study is an attempt to Insilco evaluation of the KARI as a drug target and the screened inhibitors could help in the development of the better drug against Aspergillus.
\end{abstract}

Keywords: Aspergillosis, Aspergillus, Ketol acid reductoisomerase (KARI), Pharmacophore

\section{Introduction}

Various reports from the past two decades point to the occurrence of invasive fungal infections have been greater than ever. Aspergillus represents a huge genus of economically, as well as ecologically, important fungi in industry and many fields of applied and clinical research. Aspergilli are also a leading cause of fungal morbidity and mortality in immune compromised patients [1-6]. Clinically accessible antifungal agents have quite a few downsides such as restricted potency and spectrum, non-optimal pharmacokinetics, severe resistance and drug-related toxicity. There is an emergent need to develop new antifungal drugs with a new chemical composition and novel mechanism of action [7]. Active efforts are being made by several international agencies and pharmaceutical majors to identify the drug targets and develop new drugs to treat these diseases effectively. To identify an antifungal drug targets for Aspergilli is required to develop new pharmaceuticals, to meet the challenge. Metabolic variations among organisms may be oppressive for the targets for pathogen such as Aspergilli.

\section{() Biomed Central}


Because of the huge similarity among Metabolism and enzymes with host, Eukaryotic pathogens such as Aspergilli are always being tedious to control. The information about pathogen and host and their interaction are recurring deposited. A huge database for metabolome, proteome and genome are available, which may exploit for targeting some enzyme, which could be a server for drug designing $[7,8]$. The KARI has been considered as a target for this study as a result of comparative pathway analysis between host and parasite [8]. This enzyme is involve in biosynthesis of branched chain amino acid (Valine, leucine, isoleucine), Pantothenate and CoA in Aspergillus. KARI catalyzes the conversion (s)-2 Aceto-2 hydroxybutanoate to (R)-3-hydroxy 3methyl 2-oxopentanoate and again KARI utilizes this substrate and produces (R) 2,3dihydroxy-3-methylpentanoate and converted it into Lucine and Isolucine $[8,9]$. Parallel to the above, Valine (3-hydroxy 3- methy-1,2-oxobutanoate to 2,3-dihydroxy-3-methylbutanoate) is also synthesized by same pathway. In both the reactions threonine moiety is metabolized into isolucine and valine biosynthesis in Aspergillus [10]. For the reaction catalyzed by KARI, $\mathrm{Mg}^{++}$and NADPH are required as cofactor and coenzyme respectively [11,12]. The KARI and Dihydroxy acid dehydratase are essential enzymes for biosynthesis of Lucine, Isolucine, and Valine and can be targeted as antifungal drug target. Disruption of Lucine, Isolucine and Valine biosynthetic pathway may affect the survival of the Aspergilli under the conditions of threonine limitation [8]. Thus, the KARI have selected for this study as as putative Antifungal target. In this present article we have modeled the Aspergillus KARI enzyme, using rice KARI as a template. The modeled structure was validated and used for docking study to find out drug like molecules. The identified molecules were subjected for ADME/T analysis and pharmacophore generation.

\section{Materials and methods}

The criteria for selection of Ketol acid reductoisomerase (KARI) as a drug target have reported in our last manuscript [8]. The sequences of KARI were retrieved from NCBI database http://www.blast.ncbi.nlm.nih.gov.

\section{Homology modeling}

The protein sequence was also obtained from KEGG data base http://www.genome.jp/ kegg[13] and the sequence of model of KARI was obtained from NCBI database http:// www.blast.ncbi.nlm.nih.gov[14]. Ketol acid reductoisomerase (KARI) enzyme of Aspergilli was subjected for homology modeling using Swiss model $[14,15]$. While possible active site were determined using LIGSITE ${ }^{\mathrm{csc}}$ and CASTp web servers simultaneously [16-18]. The structural homologue, which was used as a template for this model, is ketol acid reductoisomerase enzymes from rice with PDB identifier 3fr8B [19]. The sequence similarity between the template and the model is about $33 \%$. The quality of the model was verified using PROCHECK and WHAT IF $[20,21]$ a protein structure verification program. A sequence alignment of Ketol acid reductoisomerase from Rice chain -B and Aspergillus was constructed using the multiple sequence alignment program ClustalX [22].

\section{Docking}

The chemical structures of antagonists for enzyme Ketol acid reductoisomerase were extracted from ZINC. In an effort to make virtual screening more accessible to a large 
community, it is a free database of purchasable molecules, many of them "drug-like" or "lead-like", in 3D formats compatible with popular docking programs [22]. The ligand molecule was searched on drug databank by submitting the sequence of the enzyme $[22,23]$. On the basis of information obtained from drug bank, http://www.drugbank. com Library for the antagonist of Ketol acid reductoisomerase were downloaded from the Zinc server within limitation of Lipinski rule's of five [24]. The library retrieved from Zinc http://www.zinc.org was used for Docking.

The docking was performed using Molegro Virtual Docker (MVD), an evaluation version. Molegro virtual docker uses a three-dimensional structure of both protein and ligand (usually derived from X-ray/NMR experiments or homology modeling). MVD performs flexible ligand docking, so the optimal geometry of the ligand will be determined during the docking. Molegro virtual dockers explore the full range of ligand conformational flexibility with partial flexibility of the protein. Docking procedure consisted of three interrelated components; a) identification of binding site b) a search algorithm to effectively sample the search space (the set of possible ligand positions and conformations on the protein surface) and c) a scoring function or energy calculation software [25].

\section{Pharmacophore mapping}

Pharmacophore are the lead compound against a desired target. A pharmacophore is a $3 \mathrm{D}$ arrangement of functional groups within a molecule and these are necessary to bind to a macromolecule or active site Identification of the pharmacophore is an important step in understanding the interactions between receptor and ligand. This was generated with Ligandscout software [26-28]. Pharmacophore of six ligands were generated by this software and align to find out the active site of all [29].

\section{ADME/T analysis}

Pharmacokinetics a term used in the pharmacology which gives idea about Absorption, Distribution, Metabolism and Excretion/Toxicity (ADME/T) of a drug molecule. It has found that more than $50 \%$ drugs are fail during clinical trial due to their weak ADME properties [30,31]. Recent advancements in Genomics, Proteomics, High-Throughput Screening (HTS) and the overall drug discovery process have rapidly generated large numbers of potential pharmacologically active compounds waiting for optimization and pre-clinical ADMET evaluation. Thus before clinical trail ADME and toxicity property must be tested. For this analysis we have used Pharma-algorithm server http://pharma-algorithms.com/webboxes/[32].

\section{Results and discussion}

A previous study done in this laboratory about drug target identification through metabolic pathway analysis, total 40 enzymes were found to be essential for Aspergillus [8]. When amino acid sequence of KARI was compared with human proteome by BLASTp search, this enzyme was found to be non-homologous. Therefore we have targeted KARI (1.1.1.86) as putative drug target. Some other reasons which make it more interesting is its involvement biosynthesis of lucine, vsoucine and valine and these amino acids are essential for humans. Thus targeting this enzyme will not alter the amino acid metabolism in human while unavailability of these amino acids in pathogen inhibits various pathways. 
Homology based model of KARI was accomplished by swiss model server $[17,18]$ and the structural homologue, which was used as a template for this model, is ketol acid reductoisomerase enzymes from rice, The PDB identifier 3fr8B [16-18] with a resolution of $2.8 \AA$. The modeled structure was validated by UCLA server. The exact sequence similarity id about $32.19 \%$ in respect to template, therefore the sequence homology between template and subjected sequence have been analyzed by multiple sequence analysis using Clustal matrix, the results are shown in Figure 1. It was found that the KARI sequence of Aspergillus shows the conserved patches with template between 14-280 and 421-556 amino acid residues. The conserved sequences were subjected for the prediction of their functional properties. It was found to be the sequence from 14-280 belong with NADB_Rossmann protein superfamily (Rossmann-fold NAD $(\mathrm{P}) \mathrm{H} / \mathrm{NAD}(\mathrm{P})(+)$ binding (NADB) domain). The NADB domain is found in numerous dehydrogenases of metabolic pathways such as glycolysis, and many other redox enzymes. NAD binding involves numerous hydrogen-bonds and van der Waals contacts, in particular H-bonding of residues in a turn between the first strand and the subsequent helix of the Rossmann-fold topology. Characteristically, this turn exhibits a consensus binding pattern similar to GXGXXG, in which the first 2 glycines participate in $\mathrm{NAD}(\mathrm{P})$-binding, and the third facilitates close packing of the helix to the betastrand. Typically, proteins in this family contain a second domain in addition to the NADB domain, which is responsible for specifically binding a substrate and catalyzing a particular enzymatic reaction. amino acid residues between 421-556 was found to be conserved domain of IlvC superfamily enzymes. This domain is mainly associated with, catalytic domain, involved in catalysis of acetohydroxy acids to dihydroxy valerates conversion. This reaction is the second in the synthetic pathway of the essential branched side chain amino acids valine and isoleucine.

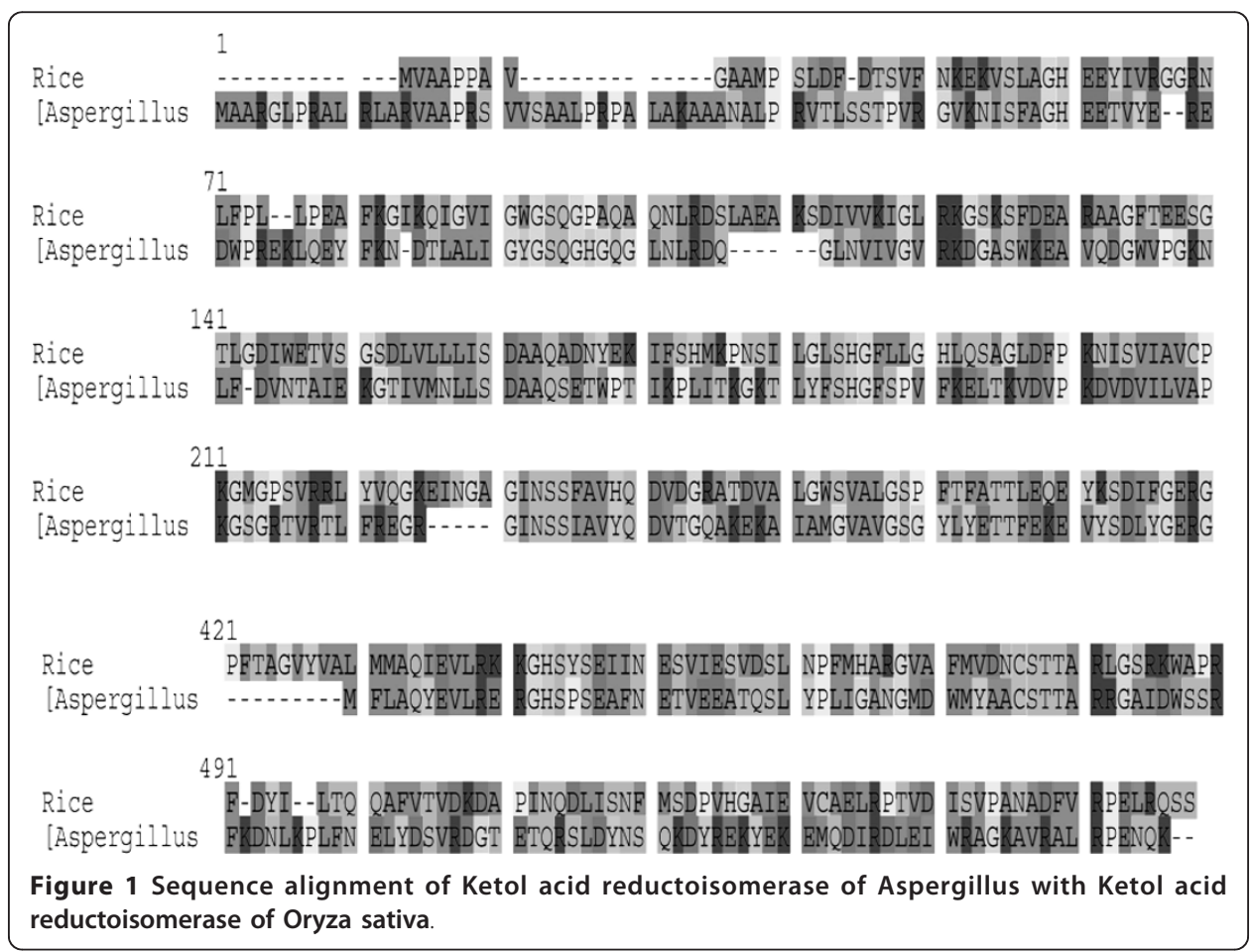


The homology based model was generated with an objective to predict structure from its sequence with an accuracy that is comparable to the best results achieved experimentally. This, allow us to safely use rapidly generated Insilico protein models in all the contexts where only experimentally generated structures provide a solid basis for structure-based drug design or rational drug designing. The structure of a protein is uniquely determined by its amino acid sequence. Knowing the sequence should, at least in theory, suffice to obtain the structure. During evolution, the structure is more stable and changes much slower than the associated sequence, so that similar sequences adopt practically identical structures and distantly related sequences still fold into similar structures $[33,34]$.

\section{Procheck validation}

The 3D structural model of KARI gerenated by homology based model has been examined by their stereo-chemical quality, by Procheck. The phi/psi angles of $85.0 \%$ residues fell in the most favored regions, $13.4 \%$ residues lied in the additional allowed regions and $1 \%$ fell in the generously allowed regions; only $0.6 \%$ of residues lied in the disallowed conformations (Figure 2). Thus, statistical analysis suggests that the backbone conformation of our predicted model of KARI was almost as good as that of the template; the 3D conformation of the predicted model of KARI has been shown in Figure 3. In the Figure 4 main chain parameters are given. These graphs represent a comparison between the structures of the model with reference, at the similar resolution. Figure 3 and four shows various properties namely Ramachandran plot, peptide bond planarity, bad non bonded interaction's alpha tetrahedral distortion, main chain hydrogen bond energy and the overall G- factor. The overall G - factor is the measure of the overall normality of the structure. After that, residue which was present in the active site of the model found out manually and also with the help of molegro software mainly three residue of amino acid was found to be associated an active site of the model of KARI these are Arg.101-ser-184 and Val- 175. Figure 3b shows the distance from active site residue to $\mathrm{N}$ - terminal and $\mathrm{C}$ - terminal [34,35]. The residues involved in the active site as predicted by LIGSITEcsc and CASTp were Arg 101, lys 169, glu 233, Asp 223, Glu 269, ser 184 and val 175 are involved in formation of cavity for binding of ligands. A previous study on Spinach, E. coli and P. aeruginosa have shown a different active site than the prediction KARI from Aspergillus [36]. The proscane analysis for pattern elucidation was done according to Bairoch and coworkers [37]. Four patterns were found on the sequence of K.A.R.I. these patterns represent N-glycosylation site, Protein kinase $\mathrm{C}$ phosphorylation site, Casein kinase II phosphorylation site and $\mathrm{N}$-myristoylation site. The above parametric comparison shows that the modeled structure is good for the further analysis like docking, to find some potential inhibitor.

\section{Docking}

The sequence of KARI was submitted to drug data bank for assessment of drug like molecule, there are three molecules available with ID DB03387; DB03675; DB04497 $[38,39]$. Based on above information the ligand library was generated using ZINC server. This library was used for docking on KARI, using Molegro virtual docker. Six ligand molecules were selected based on their docking score. After docking, total 4475 


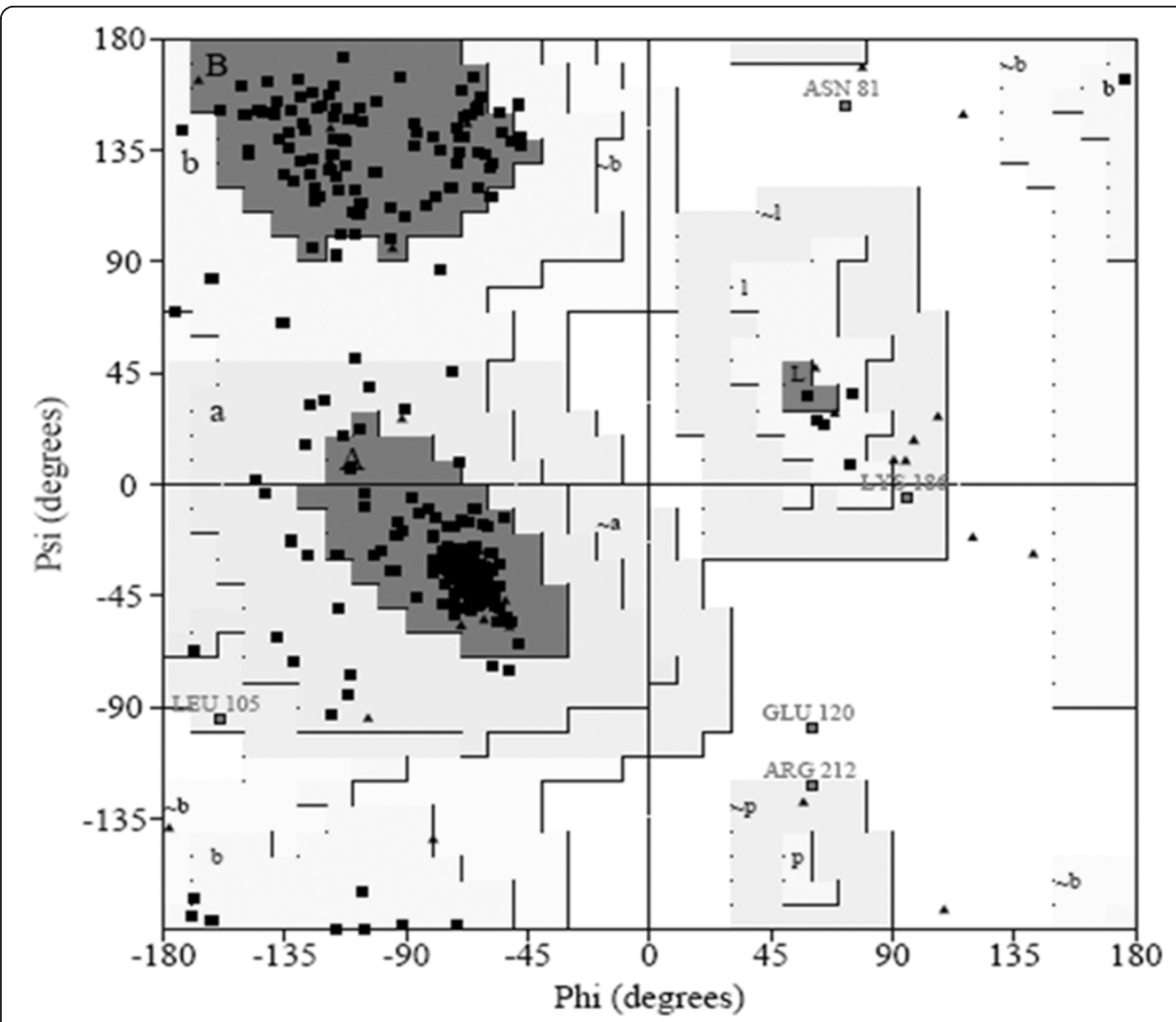

Figure 2 Ramachandran plot generated by UCLA server for validation of modeled KARI.

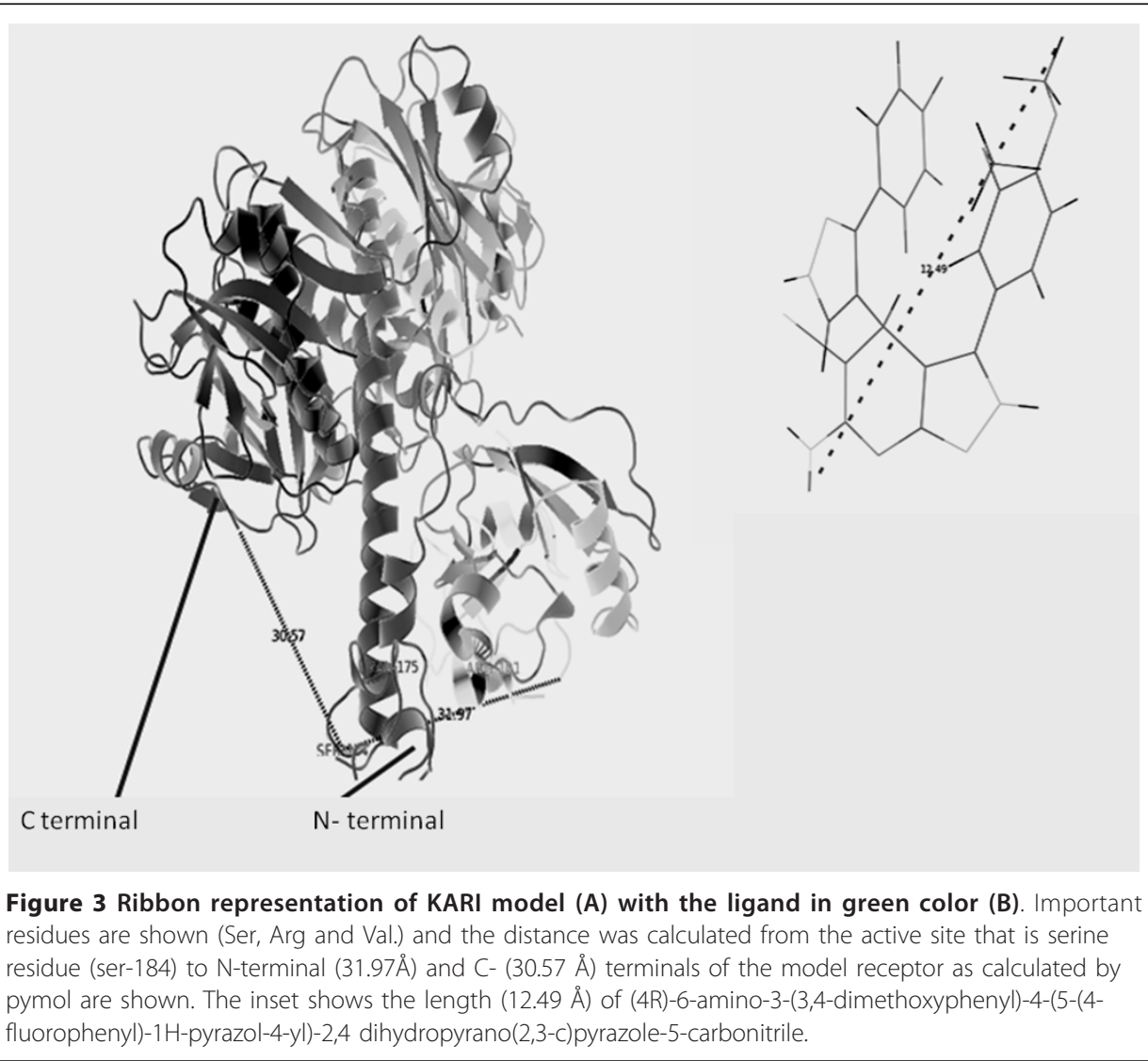




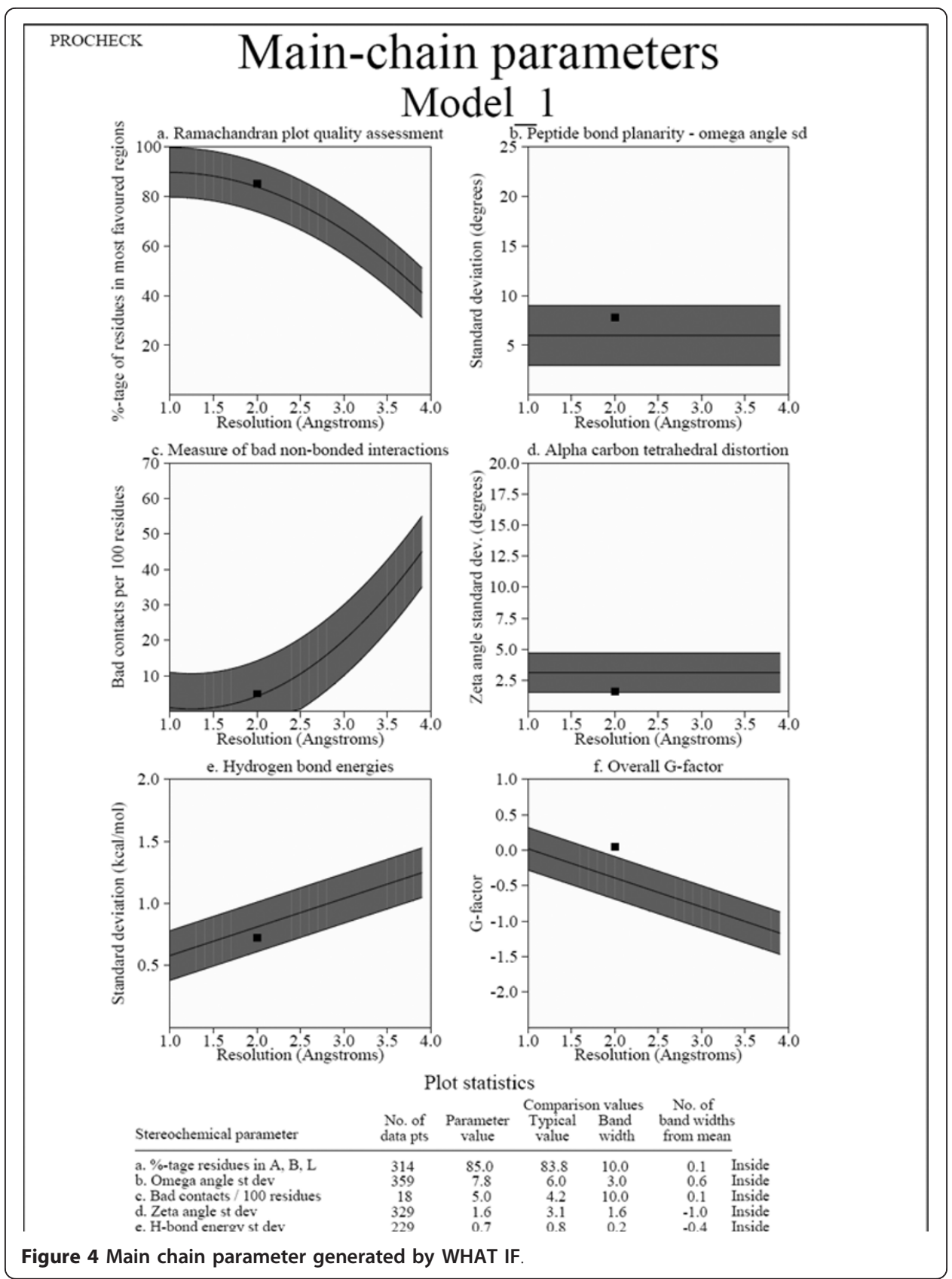

poses were obtained. On the basis docks core, minimum energy calculation, best fit poses in the cavity. The best posse from the data was selected. The various properties and molecular structure studied ligands were mentioned in table 1 . The energy score and other properties of the ligands can be selected as an inhibitor of KARI for further analysis [40].

\section{Pharmacophore mapping}

Pharmacophore mapping was accomplished by the Ligand scout software [28]. The pharmacophore models produced were evaluated qualitatively through visual inspection and according to their ability to generate the target pharmacophores. The 
Table 1 Showing various properties of ligand molecules having better score value.

\begin{tabular}{|c|c|c|c|c|c|}
\hline & ZINC I.D. & Name (IUPC) & MW & Formula & $\begin{array}{l}\text { Dock } \\
\text { score }\end{array}$ \\
\hline 12 & ZINC00720614 & $\begin{array}{l}\text { (4R)-6-amino-3-(3, } \\
\text { 4-dimethoxyphenyl)-4-[5-(4-fluorophenyl)-1 H-pyrazol-4-yl]- } \\
\text { 2,4-dihydropyrano[2,3c]pyrazole-5-carbonitrile }\end{array}$ & 458.44 & $\mathrm{C}_{24} \mathrm{H}_{19} \mathrm{FN}_{6} \mathrm{O}_{3}$ & 184.335 \\
\hline 22 & ZINC01068126 & $\begin{array}{l}\text { 6-amino-3-(2,5-dimethoxyphenyl)-4-[5-(4-fluorophenyl)-1H- } \\
\text { pyrazol-4-yl]-2, } \\
\text { 4-dihydropyrano[2,3-c]pyrazole-5-carbonitrile }\end{array}$ & 458.44 & $\mathrm{C}_{24} \mathrm{H}_{19} \mathrm{FN}_{6} \mathrm{O}_{3}$ & 164.943 \\
\hline 32 & ZINC09291743 & $\begin{array}{l}\text { 6-amino-4-(4-hydroxyphenyl)-3-(4-phenylmethoxyphenyl)- } \\
\text { 2,4-dihydropyrano[2,3-c]pyrazole-5-carbonitrile }\end{array}$ & 436.46 & $\mathrm{C}_{26} \mathrm{H}_{20} \mathrm{~N}_{4} \mathrm{O}_{3}$ & 161.478 \\
\hline 42 & ZINC02090678 & $\begin{array}{l}\text { 1-carbazol-9-yl-3-[2-(1-hydroxyethyl)benzimidazol-1-yl] } \\
\text { propan-2-ol }\end{array}$ & 387.47 & $\mathrm{C}_{24} \mathrm{H}_{23} \mathrm{~N}_{3} \mathrm{O}_{2}$ & 161.176 \\
\hline 52 & ZINC00663057 & $\begin{array}{l}\text { 2-[2-(4-amino-1,2,5-oxadiazol-3-yl) benzimidazol-1-yl]- } \mathrm{N}-[(4- \\
\text { methylphenyl) methylideneamino]acetamide }\end{array}$ & 376.39 & $\mathrm{C}_{19} \mathrm{H}_{17} \mathrm{~N}_{7} \mathrm{O}_{2}$ & 160.238 \\
\hline 62 & ZINC02284065 & $\begin{array}{l}\text { 4-[5-(4-amino-1,2,5-oxadiazol-3-yl)-2-butyl-1,2,4-triazol-3-yl]- } \\
\text { 1,2, } \\
\text { 5-oxadiazol-3-amine }\end{array}$ & 291.26 & $\mathrm{C}_{10} \mathrm{H}_{13} \mathrm{~N}_{9} \mathrm{O}_{2}$ & 158.524 \\
\hline
\end{tabular}

pharmacophore expresses constraints on the 3D structure of the molecule by specifying relative atom positions that should be maintained to increase the likelihood that the molecule will bind with the receptor site [41,42]. For all six ligand pharmacophore was generated. Figure 5 shows pharmacophore model generated with ZINC00720614, which is found to be better and could be use as a skeleton for design new class of drugs. The other Ligands namely ZINC01068126, ZINC09291743, ZINC02284065, ZINC00663057, ZINC02090678 was also used to generate pharmacophore models for comparative analysis $[23,24,43]$.

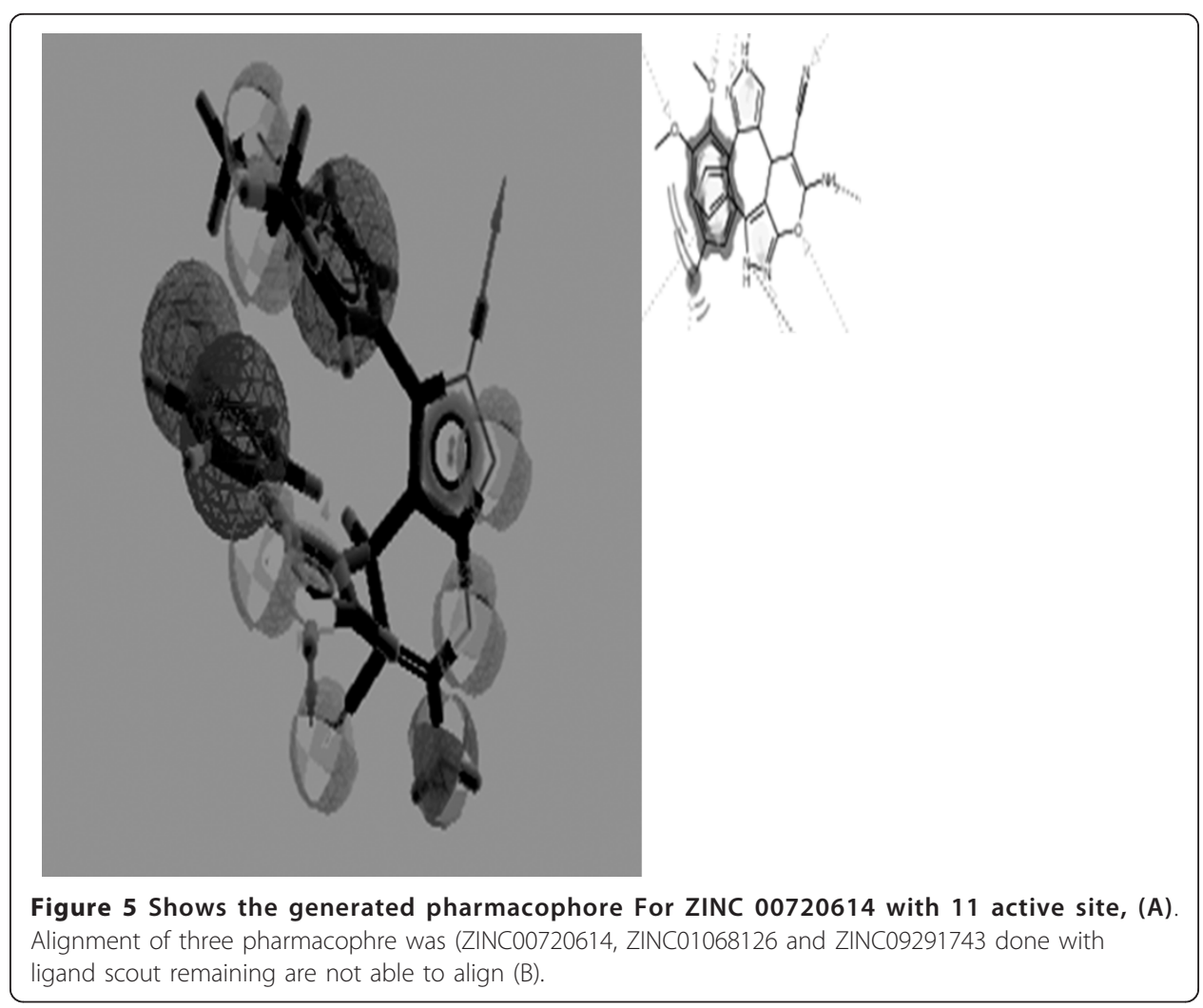




\section{ADME/Tox properties}

Absorption, Distribution, Metabolism, Excretion and Toxicity (ADME/Tox) are main five parameters to test the drug likeness of a molecule. ADME/Tox was tested by the pharma algorithm [44]. The table 2, summaries above-mentioned properties were given. Thus, the pharma algorithm gives an idea about drug likeness of the ligand molecule by studying this (table 2) can be able to know the oral bioavailability, absorption and the toxic effect of drug like molecule. By this study, it becomes easy to optimize the lethal doses of any molecule without killing any animal, which reduces the cost [45]. Oral bioavailability of drug must be low, and shows the oral bioavailability of all six ligands (Table 2). The analysis of the World Drug Index (WDI), which lead to Lipinski's 'rule-of-five' identifies several critical properties that should be considered for compounds with oral delivery in mind. These properties, which are usually viewed more as guidelines rather than absolute cutoffs, are molecular mass $<500$ daltons (Da), calculated octanol/water partition coefficient (CLOGP) $<5$, number of hydrogenbond donors $<5$ and number of hydrogen-bond acceptors $<10$. Thus, such studies point the most important physicochemical properties and structural characteristic of a good drug in the context of our current knowledge. These properties are then typically used to construct predictive ADME models and create the basis for what has been called property-based design [46]. The comparative ADME/Tox analysis of these Ligands encouraging them to use as drug like molecule, as accord [23,24,43,46,47].

\section{Conclusion}

Our previous work in which we have analyzed the metabolic pathways in the finding of essential protein, which could be targeted for drug designing. Comparative study of metabolome of the Aspergilli bestows the idea that essential enzymes can be targeted for antifungal drug designing [8], and 40 imperative proteins were identified from Aspergillus. Out of these putative targets, KARI was selected for present work, as it was found to be non-homologous protein in comparison with human protein. Therefore, targeting this protein will be Safe. Since 3D structure of KARI from Aspergilli was not reported yet so a model of this enzyme was produced by Swiss model. That model was validated by procheck and WHAT IF, programs. The structure of KARI was modeled Insilico based on X- ray crystallography structure of KARI B- chain of rice was used as the template. The ligand library was generated with the help of the drug bank from the zinc database. About 495, ligands were used in the preparation of the ligand library for docking. As a result, six ligands ZINC00720614, ZINC01068126, ZINC09291743, ZINC02090678, ZINC006637 and ZINC02284065 was selected based on docking score. It was evaluated that serine-184 was found to be a key residue along with valine and Arganine residue to form a binding site. These findings advance our knowledge on specific interactions on ZINC00720614, ZINC01068126, ZINC09291743, ZINC02090678, ZINC006637 and ZINC02284065 bind with KARI-receptor. Pharmacophore analysis was suggested about the active site of drug like molecule, and 11 such sites were deduced on ZINC00720614 ligand. This number of the active sites showed that ZINC00720614 is the best ligand molecule among all selected ligands. Maximum number of active site in a ligand molecule shows the highest chances of binding and also of lowest binding energy. The bioavailability, absorption and toxicity of the druglike molecule were studied by the pharma algorithm. Oral bioavailability stands for the 
Table 2 Pharmacophore properties of best possible drug like molecules

\begin{tabular}{|c|c|c|c|c|c|c|c|c|}
\hline \multirow[t]{2}{*}{ ZINCI.D. } & \multirow{2}{*}{$\begin{array}{l}\text { Predicted } \\
\text { values- oral } \\
\text { Bioavailability }\end{array}$} & \multirow{2}{*}{$\begin{array}{l}\text { Predicted Values } \\
\text { - Passive } \\
\text { Absorption } \\
\text { (Human } \\
\text { Intestinal) }\end{array}$} & \multirow{2}{*}{$\begin{array}{l}\text { Predicted } \\
\text { Values - } \\
\text { Probabilities of } \\
\text { Health Effects }\end{array}$} & \multicolumn{5}{|c|}{$\begin{array}{l}\text { Predicted Values- acute toxicity } \\
\text { (LD50, Mouse) }\end{array}$} \\
\hline & & & & & $\begin{array}{l}\mathrm{LD} 50 \\
(\mathrm{mg} / \mathrm{kg})\end{array}$ & pLD50 & $\begin{array}{l}\text { Lower } \\
\text { limit }\end{array}$ & $\begin{array}{l}\text { Upper } \\
\text { limit }\end{array}$ \\
\hline \multirow[t]{4}{*}{ ZINC00720614 } & less than $30 \%$ & $\begin{array}{l}\text { Maximum } \\
\text { passive } \\
\text { absorption: } \\
100 \% \\
\text { Contribution from: } \\
\text { Trancellular route } \\
=100 \% \\
\text { Paracellular route } \\
=0 \% \\
\text { Permeability: } \\
\text { Human Jejunum } \\
\text { scale }(\mathrm{pH}=6.5): \\
\text { Pe, Jejunum }= \\
3.09 \times 10^{-4} \mathrm{~cm} / \mathrm{s} \\
\text { Absorption rate: } \\
\mathrm{K}_{\mathrm{a}}=0.091 \mathrm{~min}^{-1}\end{array}$ & $\begin{array}{l}\text { Blood- } 0.99 \\
\text { Cardiovascular } \\
\text { system- } 1.00 \\
\text { Gastrointestinal } \\
\text { system-1.00 } \\
\text { Kidney }-0.99 \\
\text { Liver- } 0.98 \\
\text { Lungs-0.82 }\end{array}$ & Ip & 1000.0 & -0.34 & -1.17 & 0.42 \\
\hline & & & & 0 & 800.0 & -0.24 & -1.81 & 0.92 \\
\hline & & & & Iv & 62.0 & 0.87 & -0.18 & 2.24 \\
\hline & & & & $\mathrm{S}$ & 950.0 & -0.32 & -1.90 & 1.43 \\
\hline \multirow[t]{4}{*}{ ZINC01068126 } & less than $30 \%$ & $\begin{array}{l}\text { Ma } \times \text { imum } \\
\text { passive } \\
\text { absorption: } \\
100 \% \\
\text { Contribution from: } \\
\text { Trancellular route } \\
=100 \% \\
\text { Paracellular route } \\
=0 \% \\
\text { Permeability: } \\
\text { Human Jejunum } \\
\text { scale }(\mathrm{pH}=6.5): \\
\mathrm{Pe}, \text { Jejunum }= \\
3.42 \times 10^{-4} \mathrm{~cm} / \mathrm{s} \\
\text { Absorption rate: } \\
\mathrm{K}_{\mathrm{a}}=0.093 \mathrm{~min}^{-1}\end{array}$ & $\begin{array}{l}\text { Blood- } 0.99 \\
\text { Cardiovascular } \\
\text { system- } 1.00 \\
\text { Gastrointestinal } \\
\text { system- } 1.00 \\
\text { Kidney }-0.99 \\
\text { Liver- } 0.98 \\
\text { Lungs-0.82 }\end{array}$ & Ip & 620.0 & -0.13 & -1.01 & 0.64 \\
\hline & & & & 0 & 610.0 & -0.13 & -1.69 & 1.04 \\
\hline & & & & Iv & 48.0 & 0.98 & -0.05 & 2.27 \\
\hline & & & & $S$ & 640.0 & -0.15 & -1.73 & 1.56 \\
\hline \multirow[t]{4}{*}{ ZINC09291743 } & less than $30 \%$ & $\begin{array}{l}\text { Maximum } \\
\text { passive } \\
\text { absorption: } \\
100 \% \\
\text { Contribution from: } \\
\text { Trancellular route } \\
=100 \% \\
\text { Paracellular route } \\
=0 \% \\
\text { Permeability: } \\
\text { Human Jejunum } \\
\text { scale }(\mathrm{pH}=6.5): \\
\text { Pe, Jejunum }= \\
5.94 \times 10^{-4} \mathrm{~cm}^{\prime} \mathrm{s} \\
\text { Absorption rate: } \\
\mathrm{K}_{\mathrm{a}}=0.100 \mathrm{~min}^{-1}\end{array}$ & $\begin{array}{l}\text { Blood- } 0.98 \\
\text { Cardiovascular } \\
\text { system- } .96 \\
\text { Gastrointestinal } \\
\text { system- } 1.00 \\
\text { Kidney }-0.96 \\
\text { Liver- } 0.92 \\
\text { Lungs-0.97 }\end{array}$ & Ip & 590.0 & -0.13 & -1.13 & 0.73 \\
\hline & & & & 0 & 850.0 & -0.29 & -1.76 & 0.36 \\
\hline & & & & Iv & 43.0 & 1.00 & 0.20 & 2.40 \\
\hline & & & & $S$ & 920.0 & -0.32 & -1.91 & 1.42 \\
\hline
\end{tabular}


Table 2 Pharmacophore properties of best possible drug like molecules (Continued)

\begin{tabular}{|c|c|c|c|c|c|c|c|c|}
\hline \multirow[t]{4}{*}{ ZINC02090678 } & $\begin{array}{l}\text { between 30\% } \\
\text { and } 70 \%\end{array}$ & $\begin{array}{l}\text { Maximum } \\
\text { passive } \\
\text { absorption: } \\
100 \% \\
\text { Contribution from: } \\
\text { Trancellular route } \\
=100 \% \\
\text { Paracellular route } \\
=0 \% \\
\text { Permeability: } \\
\text { Human Jejunum } \\
\text { scale }(\mathrm{pH}=6.5): \\
\text { Pe, Jejunum }= \\
5.42 \times 10^{-4} \mathrm{~cm} / \mathrm{s} \\
\text { Absorption rate: } \\
\mathrm{K}_{\mathrm{a}}=0.100 \mathrm{~min}^{-1}\end{array}$ & $\begin{array}{l}\text { Blood- } 0.88 \\
\text { Cardiovascular } \\
\text { system- } 0.82 \\
\text { Gastrointestinal } \\
\text { system- } 0.82 \\
\text { Kidney }-0.31 \\
\text { Liver- } 0.63 \\
\text { Lungs- } 0.98\end{array}$ & Ip & 420.0 & -0.04 & -1.08 & 0.85 \\
\hline & & & & 0 & 1100.0 & -0.45 & -1.97 & 0.33 \\
\hline & & & & Iv & 54.0 & 0.85 & -0.28 & 2.30 \\
\hline & & & & $\mathrm{S}$ & 590.0 & -0.19 & -1.83 & 1.32 \\
\hline \multirow[t]{4}{*}{ ZINC00663057 } & $\begin{array}{l}\text { between 30\% } \\
\text { and } 70 \%\end{array}$ & $\begin{array}{l}\text { Maximum } \\
\text { passive } \\
\text { absorption: } \\
100 \% \\
\text { Contribution from: } \\
\text { Trancellular route } \\
=100 \% \\
\text { Paracellular route } \\
=0 \% \\
\text { Permeability: } \\
\text { Human Jejunum } \\
\text { scale }(\mathrm{pH}=6.5): \\
\text { Pe, Jejunum }= \\
3.09 \times 10^{-4} \mathrm{~cm} / \mathrm{s} \\
\text { Absorption rate: } \\
\mathrm{K}_{\mathrm{a}}=0.091 \mathrm{~min}^{-1}\end{array}$ & $\begin{array}{l}\text { Blood- } 0.61 \\
\text { Cardiovascular } \\
\text { system- } 0.36 \\
\text { Gastrointestinal } \\
\text { system- } 0.53 \\
\text { Kidney }-0.55 \\
\text { Liver- } 0.42 \\
\text { Lungs- } 0.80\end{array}$ & Ip & 300.0 & 0.09 & -0.73 & 0.71 \\
\hline & & & & 0 & 1000.0 & -0.43 & -1.89 & 0.06 \\
\hline & & & & Iv & 84.0 & 0.65 & -0.31 & 1.84 \\
\hline & & & & $S$ & 440.0 & -0.07 & -1.86 & 1.07 \\
\hline \multirow[t]{4}{*}{ ZINC02284065 } & $\begin{array}{l}\text { between 30\% } \\
\text { and } 70 \%\end{array}$ & $\begin{array}{l}\text { Maximum } \\
\text { passive } \\
\text { absorption: } \\
100 \% \\
\text { Contribution from: } \\
\text { Trancellular route } \\
=99 \% \\
\text { Paracellular route } \\
=1 \% \\
\text { Permeability: } \\
\text { Human Jejunum } \\
\text { scale }(\mathrm{pH}=6.5): \\
\mathrm{Pe}, \text { Jejunum }= \\
1.07 \times 10^{-4} \mathrm{~cm} / \mathrm{s} \\
\text { Absorption rate: } \\
\mathrm{K}_{\mathrm{a}}=0.034 \mathrm{~min}^{-1}\end{array}$ & $\begin{array}{l}\text { Blood- } 0.77 \\
\text { Cardiovascular } \\
\text { system- } 0.01 \\
\text { Gastrointestinal } \\
\text { system- } 0.77 \\
\text { Kidney }-0.38 \\
\text { Liver- } 0.43 \\
\text { Lungs- } 0.22\end{array}$ & Ip & 120.0 & 0.40 & -0.73 & 1.66 \\
\hline & & & & 0 & 510.0 & -0.24 & -1.63 & 0.66 \\
\hline & & & & Iv & 110.0 & 0.42 & -1.02 & 2.16 \\
\hline & & & & $S$ & 570.0 & -0.29 & -1.86 & 1.75 \\
\hline
\end{tabular}

\footnotetext{
** Ip- Intraperitoneal; O - Oral; Iv- Intravenous; S-Subcutaneous
} 
fraction of drug available for the mouth this six ligand molecule can be the potential drug for Aspergillosis. Uniformity of absorption of a drug-like molecule is important factors when considering its formulation and relies upon system. The minimum absorption rate constant ka value of 0.17 to 0.32 per hour necessary for about $80-95 \%$ absorption over 9-12 hrs. Absorption rate of drug provides an idea about the rate of absorption of drug like molecule and the absorption rate of these should be high, so that these molecules must be available for biological system. Thus on the basis information obtained from ADMET properties study time and cost both can be saved along with life of various animals. Therefore, homology based rational drug designing can be a successful approach for designing of potent antifungal drug. It still needed to explore some more invivo experimentation for complete evaluation as a drug. Using this selectable approach for designing the drug, a researcher can minimize the try and hit methodology, thus can save the time, cost and life of test animals. We found KARI as a potential target while design the drug against Aspergillus.

\section{Acknowledgements}

This study was supported by a grant of the Korea Healthcare Technology R\&D Project, Ministry of Health \& welfare, Republic of Korea (Grant No. A103017). The work was also supported in part by Inha University. The HIMT, Greater Noida, India, are acknowledged by the Shalini Kumari for the required support.

\section{Author details}

'Department of Biological Engineering, Inha University, Incheon, Republic of Korea, 402-751. ${ }^{2}$ Department of Biotechnology, H.I.M.T, Greater Noida, U. P., India, 201306.

\section{Authors' contributions}

VKM has designed the experimental; SK has done the computational and software operation work along VKM. VKM and EKK have analyzed the resulted. The manuscript was written by VKM and EKK. All authors read and approved the final manuscript.

\section{Competing interests}

The authors declare that they have no competing interests.

Received: 22 November 2011 Accepted: 3 February 2012 Published: 3 February 2012

\section{References}

1. Denning DW, Follansbee S, Scolaro M, Norris S, Edelstein D, Stevens DA: Pulmonary aspergillosis in AIDS. N Engl J Med 1991, 324:654-662.

2. Denning DW, Riniotis K, Dobrashian R, Sambatakou H: Chronic cavitary and fibrosing pulmonary and pleural aspergillosis: Case series, proposed nomenclature and review. Clin Infect Dis 2003, 37(3):S265-S280.

3. Denning DW: Invasive aspergillosis. Clin Infect Dis 1998, 26:781-805.

4. St. Leger RJ, Screen SE, Shams- Pirzadeh B: Lack of Host Specialization in Aspergillus flavus. App/ Environ Microbiol 2000, 66:320-324.

5. Yu J, Cleveland TE, Nierman WC, Bennett JW: Aspergillus flavus genomics: gateway to human and animal health, food safety, and crop resistance to diseases. Rev Iberoam Micol 2005, 22:194-202.

6. Morya VK, Nayak S, Mishra SK, Kamal Yadav D: Morphological characteristics and total mycelial protein profile of indigenously isolated Aspergillus strains. J Mycol PI Pathol 2009, 39(2):216-219.

7. Morya VK, Dewaker V, Mecarty SD, Singh R: In silico analysis of metabolic pathways for identification of putative drug targets for Staphylococcus aureus. J Comput Sci Syst Biol 2010, 3(3):062-069.

8. Morya VK, Kumari S, Kim Eun-Ki: Imperative pathway analysis to identify the potential drug target for Aspergillus infection. International Journal of Latest Trends in Computing 2011, 2(1):178-182.

9. Bryan J: Synthesis of the aspartate family and branched-chain amino acids. In The Biochemistry of Plants. A Comprehensive Treatise. Volume 5. Edited by: Miflin BJ. Academic Press, New York; 1980:403-453.

10. Aulabaugh A, Schloss JV: Oxalyl hydroxamates as reactionintermediate analogues for ketol-acid reductoisomerase. Biochemistry 1990, 29:2824-2830.

11. Chunduru SK, Mrachko GT, Calvo JC: Mechanisms of ketol acid reducto isomerase-steady state analysis and metal ion requirement. Biochemistry 1989, 28:486-493.

12. Dumas R, Joyard J, Douce R: Purification and characterization of acetohydroxyacid reductoisomerase from spinach chloroplasts. Biochem J 1989, 262:971-976.

13. KEGG - Kyoto Encyclopedia of Gene and Genome. [http://www.genome.jp/kegg].

14. NCBI - National Center for Biotechnology Information. [http://www.blast.ncbi.nlm.nih.gov]

15. Morya VK, Yadav S, Kim EK, Yadav D: In silico characterization of alkaline proteases protein sequences of different species of Aspergillus. Appl Biochem Biotechnol 2011, DOI: 10.1007/s12010-011-9420-y. 
16. Peitsch MC: Protein modeling by E-mail. Nature Biotechnology 1995, 13:658-660.

17. Kiefer F, Arnold K, Künzli M, Bordoli L, Schwede T: The SWISS-MODEL Repository and associated resources. Nucleic Acids Res 2009, 37:D387-D392.

18. Arnold K, Bordoli L, Kopp J, Schwede T: The SWISS-MODEL Workspace: A web-based environment for protein structure homology modelling. Bioinformatics 2006, 22:195-201.

19. Laskoswki RA, MacArthur MW, Moss DS, Thorton JM: PROCHECK: a program to check the stereochemical quality of protein structures. J Appl Cryst 1993, 26:283-291.

20. Hooft RWW, Vriend G, Sander C, Abola EE: Errors in protein structures. Nature 1996, 381:272-272.

21. Thompson JD, Gibson TJ, Plewniak F, Jeanmougin F, Higgins DG: The ClustalX windows interface: flexible strategies for multiple sequence alignment aided by quality analysis tools. Nucleic Acids Res 1997, 24:4876-4882.

22. Irwin JJ, Shoichet BK: ZINC - A Free Database of Commercially Available Compounds for Virtual Screening. J Chem Inf Model 2005, 45(1):177-182

23. Wishart DS, Knox C, Guo AC, Cheng D, Shrivastava S, Tzur D, Gautam B, Hassanali M: DrugBank: a knowledgebase for drugs, drug actions and drug targets. Nucleic Acids Res 2008, 36(1):D901-6.

24. Lipnski CA, Lombardo F, Dominy BW, Feeny PJ: Experimental and computational approach to estimate solubility and permeability in drug discovery and development setting. Adv Drug Deliver Rev 2001, 1:3-26.

25. Thomsen R, Christensen MH: MolDock: A New Technique for High-Accuracy Molecular Docking. J Med Chem 2006, 49(11):3315-3321.

26. Hendlich M, Rippmann F, Barnickel G: BALl: Automatic assignment of bond and atom types for protein ligands in the brookhaven protein databank. J Chem Inf Comput Sci 1997, 37:774-778.

27. Berman HM, Westbrook J, Feng Z, Gilliland G, Bhat TN, Weissig H, Shindyalov IN, Bourne PE: The protein data bank. Nucleic Acids Res 2000, 28:235-242

28. Wolber $\mathrm{G}$, Langer $\mathrm{T}$ : Combigen: A novel software package for the rapid generation of virtual combinatorial libraries. In Rational Approaches to drug design, Prous Science Edited by: Höltje H-D, Sippl W 2000, 390-399.

29. Wolber G, Kosara R: Pharmacophores from macromolecular complexes with LigandScout. In Pharmacophores and Pharmacophore Searches Edited by: Langer T, Hoffmann RD 2006, 32:131-150, Wiley-VCH.

30. Balakin KV, Ivanenkov YA, Savchuk NP, Ivashchenko AA, Ekins S: Comprehensive Computational Assessment of ADME Properties Using Mapping Techniques. Current Drug Discovery Technologies 2005, 2:99-113.

31. Rönn O, Öhman J, Haid D, Nordvarg H, Hörnsten L, Flensburg J, Forsberg E, Fenyö D, Bergling H, Woffendin G, Scigelova M: GE Healthcare, Uppsala, Sweden, 2Thermo Fisher Scientific, Hemel Hempstead, UK Proteomics in ADME/Tox Studies: High-Throughput Identification and Differential Expression Analysis of Proteins in Mouse Liver Following Drug Treatment. 2007, Applicationj Note, 345.

32. Pharma algorithm. [http://www.pharma.algorithm.com].

33. Chothia C, Lesk AM: The relation between the divergence of sequence and structure in proteins. EMBO J 1986, 5:823-36.

34. Sander C, Schneider R: Database of homology-derived protein structures and the structural meaning of sequence alignment. Proteins 1991, 9:56-68.

35. Vijayan R, Subbarao N, Mallick BN: Insilico Modeling of alpha1A-Adrenoceptor: Interaction of its Normal and Mutated Active Sites with Noradrenaline as well as its Agonist and Antagonist. Am J Biochem \& Biotech 2007, 3(4):216-224.

36. Tyagi R, Duquerroy S, Navaza J, Guddat LW, Duggleby RG: The crystal structure of a bacterial class II ketol-acid reductoisomerase: domain conservation and evolution. Protein Sci 2005, 14(12):3089-100.

37. Bairoch A, Bucher P, Hofmann K: The PROSITE database, its status in 1997. Nucleic Acids Res 1997, 25(1):217-221.

38. Stephen FA, Madden TL, Schaffer AA, Zhang J, Zhang Z, Miller W, Lipman DJ: Gapped BLAST and PSI-BLAST: a new generation of protein database searchprograms. Nucleic Acids Res 1997, 25:3389-3402.

39. Stephen FA, Wootton JC, Gertz EM, Agarwala R, Morgulis A, Schaffer AA, Yu KY: Protein database searchesusing compositionally adjusted substitution matrices. FEBS J 2005, 272:5101-5109.

40. Wieman H, Tøndel K, Anderssen E, Drabløs F: Homology-Based Modelling of Targets for Rational Drug Design. Mini Rev Med Chem 2004, 4:793-804.

41. Wolber G, Seidel T, Bendix F, Langer T: Molecule-pharmacophore superpositioning and pattern matching in computational drug design. Drug Discovery Today 2008, 13(1/2):23-29.

42. Lavalle SM, Finn PW, Kavraki LE, Latombe JC: A Randomized Kinematics-Based Approach to PharmacophoreConstrained Conformational Search and Database Screening. J Comput Chem 2000, 21(9):731-747.

43. Lipinski CA: Drug-like properties and the causes of poor solubility and poor permeability. J Pharmacol Toxicol Methods 2001, 44:235-249.

44. Ekins S: Systems-ADME/Tox: Resources and network approaches. J Pharmacol Toxicol 2006, 53:38-66.

45. Nicholson JK, Wilson ID: Understanding global, systems biology: Metabonomics and the continuum of metabolism. Nat Rev Drug Discov 2003, 2:668-676.

46. Van de Waterbeemd H, Gifford E: ADMET Insilico Modelling: Towards Prediction Paradise? Nat Rev Drug Discov 2003, 2:192-204.

47. Van de Waterbeemd H, Smith DA, Beaumont K, Walker DK: Property-based design: Optimisation of drug absorption and pharmacokinetics. J Med Chem 2001, 44:1313-1333.

Cite this article as: Morya et al:: Virtual screening and evaluation of Ketol-Acid Reducto-lsomerase (KARI) as a putative drug target for Aspergillosis. Clinical Proteomics 2012 9:1. 